\title{
The Whooping Crane Problem
}

Mr. Fred Bard has just returned from Washington, D.C. where he was one of a score of migratory bird and wildlife experts who met to discuss the precarious position of the Whooping Crane. It was agreed that some substantial management plans must be made and that an international committee would be appointed by the United States and Canadian wildlife officials to explore the problem fully.

In the accompanying sketch maps of Southern Saskatchewan prepared by Mr. Bard the black ovals show places where the birds were positively identified and photographed using telephoto lens. The white ovals are positive identifications but they are not substantiated by photographs.

These records all fall within the rather narrow migration pathway which was described by Mr. Bard in the BLUE JAY, Volume XIV, No. 2, page 41, June 1956. The number of records prove that the Saskatchewan plains are extremely important to the Whooping Cranes during both the spring and fall migration. The fact that the Cranes need cur area for focd and rest during their long migration places a heavy respor: ibility on Saskatchewan people for the survival of these rare birds. First, we can refrain from shooting whenever there are white birds in the neighborhood. The October 30 News Re'ease from the U.S. Fish and Wildlife Service tells of hunters refraining from shooting at hundreds of White-fronted Geese at Harlan County Reservoir because there were two Whooping Cranes resting in the area. Second, we can refrain from molesting the birds while they are feeding in our fields. They are extremely wary and are easily disturbed. If you wish a closer look borrow fieldglasses or telescope and look at them from the roadway.

On October 26 there were 13 Cranes back in the Aransas Refuge in Texas. The first five to return, including one young-of-the-year, were described by observers to be so tired that "for a long while they huddled in the marsh, wings drooping and heads down, apparently

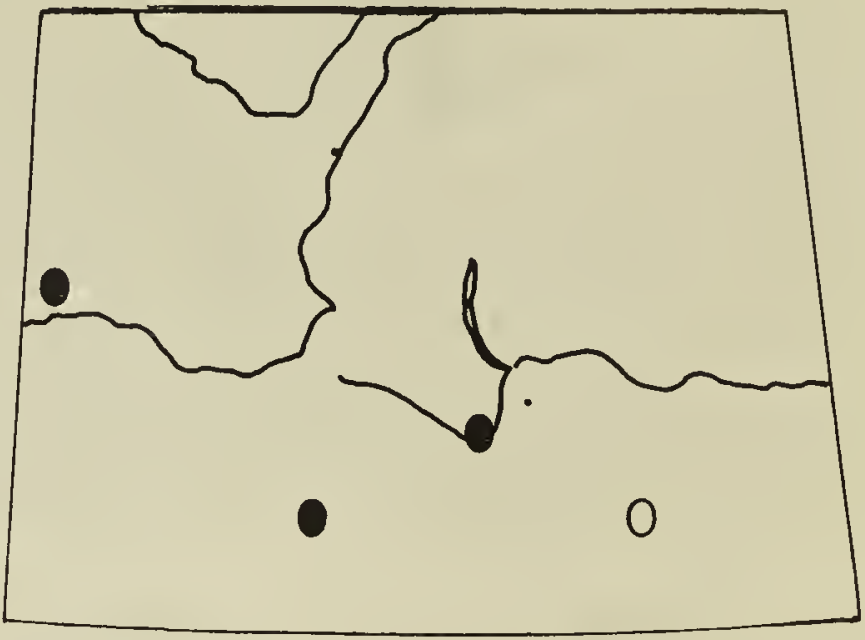

Spring Migration 1956

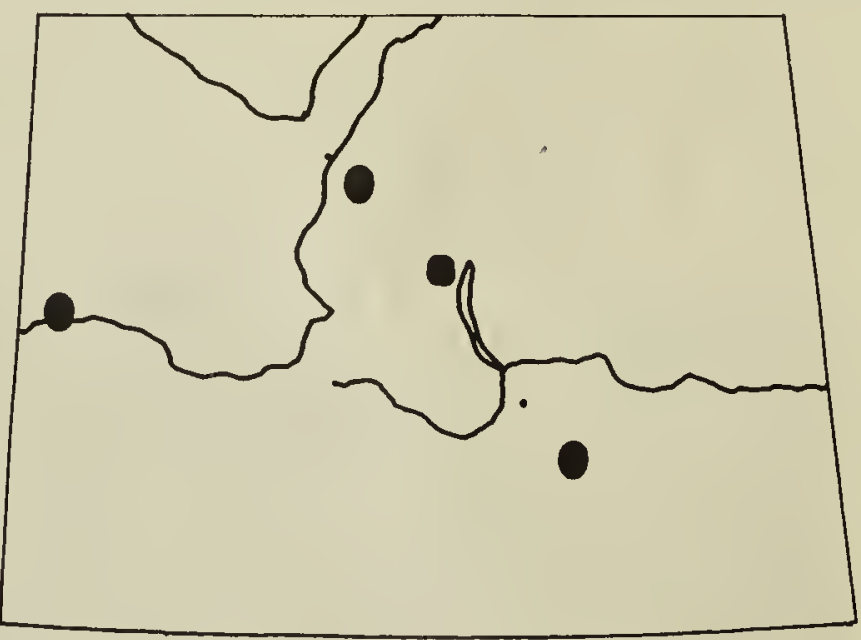

Summer Wanderers 1956

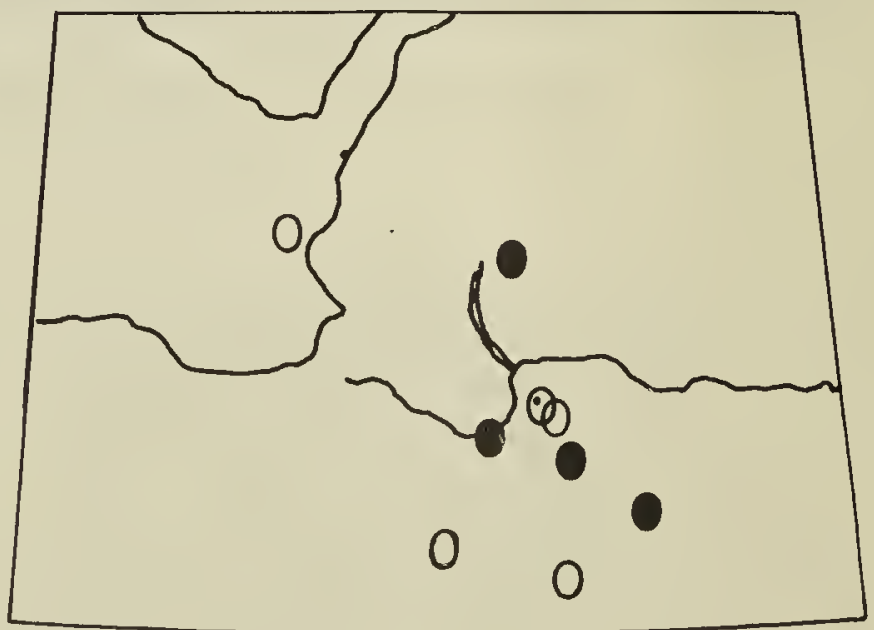

Fall Migration 1956

exhausted from the long flight which started days and days ago from the Canadian northland near Great Slave Lake." At the same time there were still Cranes in Saskatchewan.

The accompanying photo of three Whooping Cranes taken at Osage on 


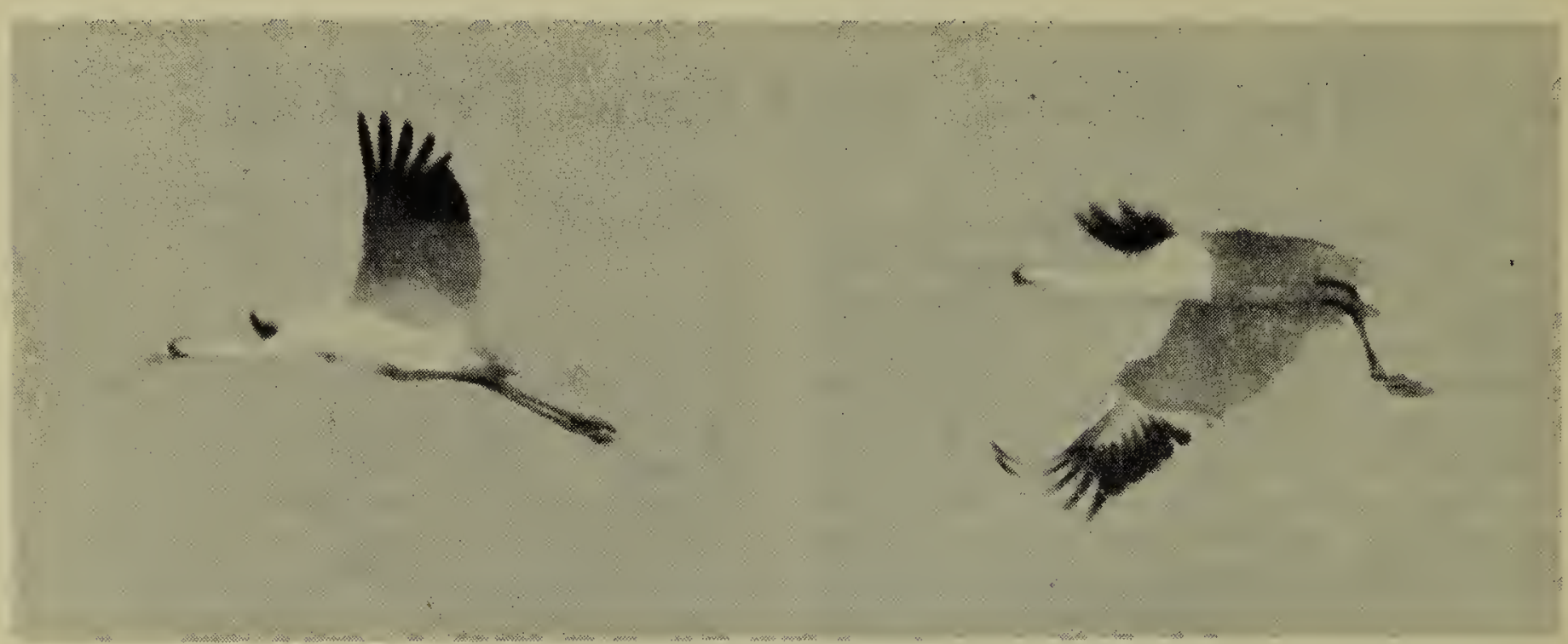

Photo by F. W. Lahrman

Whooping Cranes in flight at Milestone, Sask., October 18, 1956

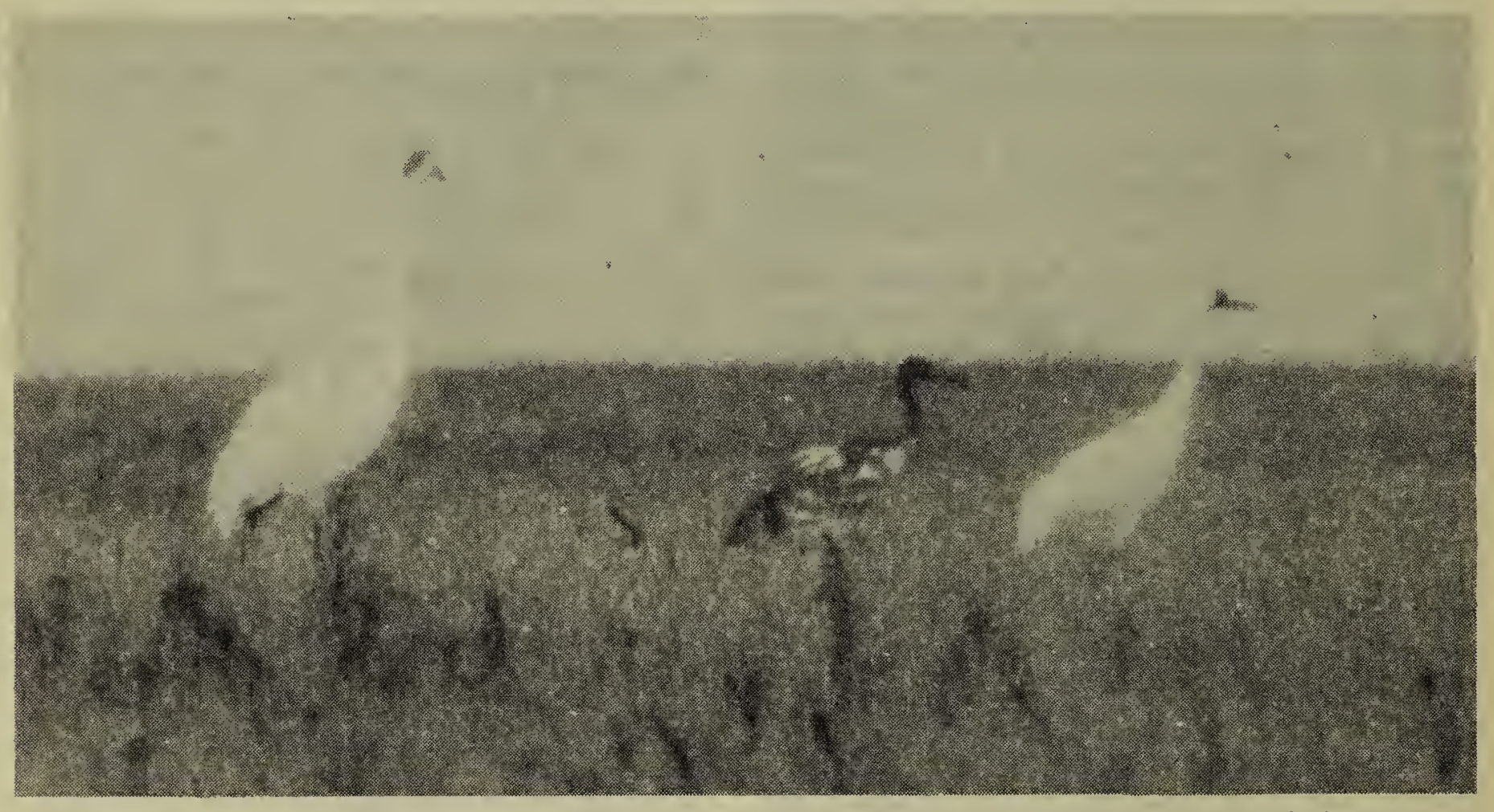

Photo by F. W. Lahrman

Pair with young at Osage, Sask., October 24, 1956

October 24 is remarkable in that it is the first photo of a young-of-theyear taken during fall migration. This young bird is surprisingly dark. Actually very little is known about young Whooping Cranes so perhaps this is the normal color for birds of this age. These birds have caused the museum officials considerable concern because they stayed on in this area during the heavy snowfall of October 27. Food was then hard to find and the temperature dropped to nearly zero.

The Whooping Crane problem seems to spring from the fact that settlement of the Saskatchewan plains has driven these shy birds northward. There the nesting season is from 30 to 60 days shorter than normal and the severe weather is too great a handicap for the small population to overcome. Some years no young are raised. Last year eight young reached Aransas safely. This year there are at least two young birds. The picture is gloomy but the few individual Whoopers left seem to have lots of vitality.

Saskatchewan people are "Whooper conscious" and they will back to the limit any program which might give the Whooping Crane a better chance to climb to a higher and safer population level. 